\title{
Vitamin D status and dental caries in healthy Swedish children
}

\author{
Johanna Gyll' , Karin Ridell², Inger Öhlund ${ }^{3}$, Pia Karlsland Åkeson ${ }^{4}$, Ingegerd Johansson ${ }^{5}$ \\ and Pernilla Lif Holgerson ${ }^{1 *}$ (D)
}

\begin{abstract}
Background: Vitamin D is crucial for mineralized tissue formation and immunological functions. The purpose of this study was to evaluate the association between vitamin D status and dental status in healthy children with vitamin D supplementation in infancy and at 6 years of age.

Method: Eight-year-old children who had participated in a vitamin D intervention project when they were 6 years old were invited to participate in a dental follow-up study. They had fair or darker skin complexion and represented two geographically distant parts of Sweden. 25-hydroxy vitamin $D$ in serum had been measured at 6 years of age and after a 3-month intervention with 25, 10 or 2 (placebo) $\mu \mathrm{g}$ of vitamin $\mathrm{D}_{3}$ per day. Two years later, caries and enamel defects were scored, self-reported information on e.g., oral behavior, dietary habits and intake of vitamin $D$ supplements was collected, and innate immunity peptide LL37 levels in saliva and cariogenic mutant streptococci in tooth biofilm were analyzed. The outcome variables were caries and tooth enamel defects.
\end{abstract}

Results: Dental status was evaluated in 85 of the 206 children in the basic intervention study. Low vitamin D levels were found in $28 \%$ at baseline compared to $11 \%$ after the intervention, and 34\% reported continued intake of vitamin D supplements. Logistic regression supported a weak inverse association between vitamin D status at 6 years of age and caries 2 years later (odds ratio $0.96 ; p=0.024$ ) with minor attenuation after an adjustment for potential confounders. Multivariate projection regression confirmed that insufficient vitamin D levels correlated with caries and higher vitamin D levels correlated with being caries-free. Vitamin D status at 6 years of age was unrelated to enamel defects but was positively associated with saliva LL37 levels.

Conclusion: An association between vitamin D status and caries was supported, but it was not completely consistent. Vitamin D status at 6 years of age was unrelated to enamel defects but was positively associated with LL37 expression.

Trial registration: The basic intervention study was registered at ClinicalTrials.gov with register number NCT01741324 (www.clinicaltrials.gov/ct2/show/NCT02347293) on November 26, 2012.

Keywords: Vitamin D - Children - caries - enamel defects - LL37

\section{Background}

Vitamin D is associated with a broad spectrum of biological functions owing to its endocrine, autocrine and paracrine activities [1]. Its reported functions include the regulation of calcium and phosphate metabolism and their deposition in mineralized tissues [2, 3], effects on innate immunity effectors [4], involvement in cognitive functions, roles in blood pressure maintenance and effects related to health

\footnotetext{
* Correspondence: pernilla.lif@umu.se

'Department of Odontology, Section of Paediatric Dentistry, Faculty of Medicine, Umeå University, 90185 Umeå, Sweden

Full list of author information is available at the end of the article
}

outcomes (cardiometabolic conditions, total mortality and aging) $[5,6]$. Children and adolescents are particularly vulnerable to the clinical manifestations of insufficient vitamin D because of its central role in bone and tooth formation [3].

Generally, serum 25-hydroxy vitamin D [S- $(25(\mathrm{OH}) \mathrm{D}]$ levels below $<30 \mathrm{nmol} / \mathrm{L}$ are considered deficient, $50 \mathrm{nmol} / \mathrm{L}$ are insufficient, and $>75 \mathrm{nmol} / \mathrm{L}$ are suggested as optimal for health [7-9]. According to epidemiological studies, insufficient levels of vitamin D are common in children and adolescents [10] with a higher prevalence reported in areas with less sunshine and in populations with 
protection against sun exposure or with dark skin complexions [11, 12]. 25-hydroxyvitamin D status is determined by measuring its circulating forms in serum, including the $\mathrm{D}_{2}$ and $\mathrm{D}_{3}$ variants [2,7]. Most foods contain relatively small amounts of vitamin $D$. major natural sources include oily fish and eggs, which contain $D_{3}$, and many countries, including Sweden, fortify table spreads and milk with vitamin $\mathrm{D}_{3}$.

The function of vitamin D in tooth development implies that impaired tooth composition is more prevalent in subjects with vitamin D deficiency [13], but the association may be overlooked since clinical manifestations appear after a significant delay $[10,14]$. Based on the effects of vitamin D on tooth quality and the innate immune system, including the defensins and cathelicidins (LL37) [4], studies have evaluated the association between vitamin D levels and dental caries; however, the results are conflicting. Thus, according to some studies, low vitamin D levels/intakes are associated with higher caries prevalence [14-16], but other studies have not observed an association [17]. A recent systematic review of clinical trials assessing the effect of vitamin $\mathrm{D}$ on the prevention of dental caries yielded a weak positive effect of vitamin D supplementation with no clear difference in the positive effect between supplementation route, i.e., vitamin $D_{2}$, vitamin $D_{3}$, or ultraviolet radiation [18]. Other studies have assessed associations between vitamin $\mathrm{D}$ receptor (VDR) polymorphisms or a combined genetic risk score and dental caries, but these studies have also produced conflicting results $[15,19,20]$. Therefore, further clarification is needed to determine the reasons for the conflicting results, such as studies targeting defined populations and careful monitoring of confounding factors and sufficient variations in vitamin $D$ status.

The primary aim of the present study was to evaluate the association between the vitamin $\mathrm{D}$ status of 6-yearold children and their caries status 2 years later. A secondary goal was to evaluate associations of vitamin $\mathrm{D}$ status with tooth enamel disturbances and levels of the innate immunity peptide LL37.

\section{Methods}

\section{Ethical approval}

The basic intervention study (DViSUM) was registered at ClinicalTrials.gov (NCT01741324) and approved by the Regional Ethical Review board at Umeå University (Reference: 2012-158-31 M). An addendum was approved (Reference: 2014-103-32 M) for the present dental follow-up study. Data were collected and analyzed according to the guidelines of the Declaration of Helsinki (including written consent from caretakers and children for participation), the Swedish Law on personal data act (PuL) and Law on biobanking, and the guidelines of the Swedish Data Inspection Board.

\section{Subjects}

The present study recruited 8-year-old children who had participated in an intervention study on milk-based vitamin D supplementation at 6 years of age (DViSUM) [21, 22]. DViSUM included 206 children who were proportionally distributed across different living regions [northern Sweden (Umeå, $63^{\circ} \mathrm{N} ; n=85$ ) and southern Sweden (Malmö, $55^{\circ} \mathrm{N} ; n=121$ )] and were selected to represent both fair $(n=108)$ and darker skin $(n=98)$ complexions. To be included, the children had to be regular milk consumers. Baseline examinations in DViSUM occurred in November and December of 2012 and included anthropometric measures, blood sampling and questionnaires on information about diet intake and socioeconomic conditions. At the first visit in DViSUM, children were randomly assigned to receive 25,10 or 2 (placebo group), $\mu \mathrm{g}$ of vitamin $\mathrm{D}_{3}$ per day in a milk-based supplement for 3 months. Follow-up blood samples were collected when the 3-month intervention period was completed.

Of the 206 children who participated in DViSUM, 85 (41\%) consented to participate in an examination of their dental status. Of the 85 children, $37(42 \%)$ in the $25 \mu \mathrm{g}$ per day group, 38 (45\%) in the $10 \mu \mathrm{g}$ per day group, and $10(12 \%)$ were in the placebo group, and compared to $42 \%, 39 \%$ and $19 \%$, respectively, in the basic study [22]. Dental follow-up occurred in the latter half of 2014. The major reason for non-participation was that the children's caretakers had moved out of the specified geographic areas. A flow diagram is shown in Fig. 1.

The general characteristics of the study population were low to moderate caries activity and organized dental care from 2 to 3 years of age, including compulsory caries prevention programs. Furthermore, supplementation with vitamin D3 drops (10 $\mu \mathrm{g} /$ day $)$ was strongly encouraged from birth to 2 years of age and up to 5 years in children with dark skin complexions [23].

\section{Dental examination and data collection}

All children were examined by an experienced dentist (JG or KR) for dental caries and enamel defects. At this visit, a questionnaire on tooth brushing and other dental healthrelated behaviors, including diet with focus on sugar and vitamin D containing foods/food aggregates, use of fluoride and supplements, and health status, medication, and socio-economic information, was administered. All examinations were performed in well-equipped dental offices with good lighting conditions. Caries status was determined by the surface-related decayed-missing-filled index [24], but the missing component was not included since teeth were not lost because of caries. Initial caries and fissure sealants were not included in the decayed and filling components, respectively. Therefore, the permanent dentition $\mathrm{D}_{3-4} \mathrm{FS}$ and the primary dentition $\mathrm{d}_{3-4}$ fs were 


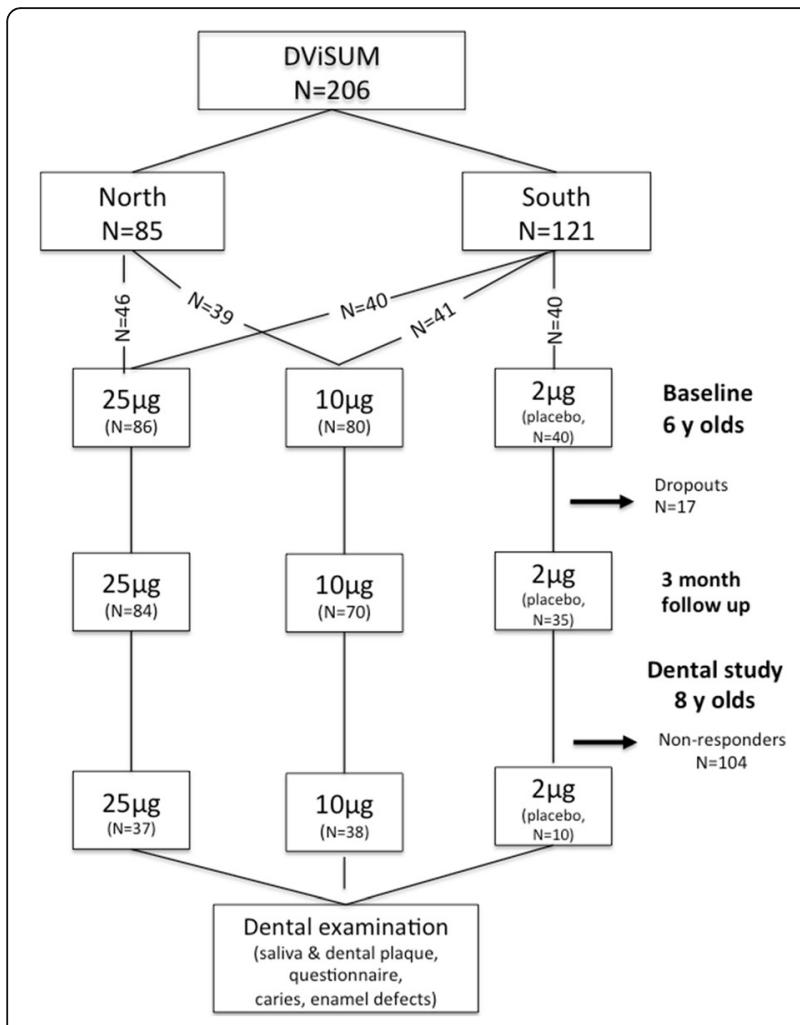

Fig. 1 Flow diagram of the numbers of children in the basic intervention DViSUM and placebo groups at baseline, 3 month follow up and at the dental follow up at 8 years of age

scored (scores 3-4 represent caries lesions into the dentine). The combined measures of $D_{3-4} \mathrm{FS}$ and $d_{3-4}$ fs are hereafter referred to as dfs/DFS. Bitewing radiographs were captured for special indications, such as when approximal tooth surfaces were unavailable for visual inspection.

Enamel defects were documented and evaluated from photos captured during the clinical examination using criteria defined by the Commission on Oral Health, Research \& Epidemiology [25]. Enamel defects, i.e., opacities and signs of enamel hypoplasia, were scored on a 6level scale, where a score of 0 represents sound enamel and scores of 1-6 represent increasing severity of opacities and hypoplasia. The number of permanent first molars and central upper and lower incisors with a score of 0 or $\geq 1$ were registered.

The scoring of enamel defects was trained and calibrated among two evaluating dentists (JG and KR) and a senior consultant in pediatric dentistry (PLH). Training was conducted with intra-oral photos from anonymous, non-study patients with various manifestations of enamel defects. Diverging scores were discussed to reach a consensus. Reproducibility rates were calculated for the occurrence of enamel defects. The intra-examiner weighted kappa-values (к) ranged between 0.96 and 0.98 . Inter- examiner agreement for the scoring of enamel defects was evaluated using photographs from 10 randomly selected participating children with a $\mathrm{k}$-value of 0.81 .

\section{Tooth biofilm and saliva sampling and analyses}

Tooth biofilm was collected for PCR detection of the caries associated Streptococcus mutans and Streptococcus sobrinus. Samples were collected from all available supragingival tooth surfaces using sterilized toothpicks, pooled for each participant and stored in TE buffer $(10 \mathrm{mM}$ Tris and $1 \mathrm{mM}$ EDTA, pH 7.6) at $-80{ }^{\circ} \mathrm{C}$. Genomic DNA was extracted and quality controlled as previously described [26]. The presence of S. mutans and S. sobrinus was detected using SmF5 and SmR4 primers for S. mutans and SsF3 and SsR1 primers for S. sobrinus [27].

Paraffin chewing-stimulated whole saliva $(3 \mathrm{~mL})$ was collected into ice-chilled test tubes for the analysis of LL37 levels. Samples were aliquoted and stored at $-80^{\circ}$ $\mathrm{C}$ until further analysis.

\section{Anthropometric measures}

Height and body weight were measured at the baseline DViSUM visit $[21,22]$, and body mass index, BMI $\left(\mathrm{kg} / \mathrm{m}^{2}\right)$, was calculated and converted to a BMI z-score based on WHO reference data for children and adolescents aged 5 to 19 years [28].

\section{Serum and plasma analyses}

Serum 25(OH)D and vitamin D-related components, i.e., calcium, phosphate, magnesium, parathyroid hormone $(\mathrm{PTH})$, alkaline phosphatase (ALP), and osteocalcin in plasma, were analyzed before and after the intervention period as previously described [21, 22]. Briefly, venous blood samples were collected at least $2 \mathrm{~h}$ after a meal. The samples were light protected, centrifuged after $30 \mathrm{~min}$, and stored at $-20{ }^{\circ} \mathrm{C}$ for up to a week and then at $-80{ }^{\circ} \mathrm{C}$. S- 25(OH) vitamin D2 and S-25(OH) vitamin D3 levels were analyzed by mass spectrometry on an API $4000 \mathrm{LC} /$ MS/MS system (AB Sciex, Framingham, MA). All other components were analyzed in plasma on Cobas 6000/ 8000 analyzers (Roche Diagnostics, Mannheim, Germany). Serum levels of $25(\mathrm{OH}) \mathrm{D}<50 \mathrm{nmol} / \mathrm{L}$ were considered insufficient, and levels $<30 \mathrm{nmol} / \mathrm{L}$ were considered deficient [29].

\section{LL37 analysis in saliva}

LL37 levels were analyzed using the LL37 Human ELISA kit (HK321, Hycult Biotech, Uden, The Netherlands) according to the manufacturer's instructions. Briefly, thawed samples were centrifuged, and the supernatant was transferred to antibody-coated microtiter wells to capture LL37, incubated with a biotinylated secondary antibody and detected by streptavidin-peroxidase. 


\section{Data handling and statistical analyses}

Continuous, normally distributed variables are presented as the means with 95\% confidence limits (CI). Differences between group means were either evaluated with Student's t-test for comparisons between two groups and ANOVA for more than two groups. Differences in dietary intake were tested with the Mann-Whitney nonparametric test. When appropriate, mean values were standardized for potential confounders, such as living region, skin type, and vitamin D supplement intake, using general linear modeling $(\mathrm{glm})$. Categorical variables are presented as numbers or proportions, and the $\mathrm{Chi}^{2}$ test was used to determine differences in distributions. All tests were two-sided, and $p$-values $<0.05$ were considered statistically significant.

Logistic regression analysis was used to evaluate the adjusted odds ratio (OR) and 95\% confidence limits (CI) for caries with vitamin D status as the independent variable and potential confounders included as covariates. Vitamin D was evaluated as a continuous measure. A dichotomous caries classification (caries-free or cariesaffected) was used to account for zero-inflated dfs/DFS scores. Three models were evaluated: model 1 (basic model) was adjusted for the number of teeth, tooth brushing (once or twice a day), presence or absence of $S$. mutans, father's education level $(<12$ years or $\geq 12$ years of school attendance), and region of residence; model 2 also included BMI (z-scores) and intake of a vitamin D supplement at the time of the dental examination; and model 3 also included skin type. Since all blood samples were collected in the same season, adjustment for season was not needed. Further adjustments, including the parents' country of origin and reported intake of various sweet products, were tested, but they did not affect the results. Firth's penalized likelihood approach was used to address the small group sizes using proc. logistic in SAS 9.4 (SAS Institute Inc., Cary, NC, USA) and odds ratios with and without correction are presented.

Multivariate principal component analysis (PCA) and partial least square (PLS) regression analyses were used to search for clustering of subjects and variables associated with caries (yes/no) and number of teeth with defective enamel, respectively. Following a screening step in which variables that were influential in explaining the variation in the dependent variables, i.e., Variable Importance in Projection (VIP) values $>1$ among all serum/plasma components, anthropometric measures, diet, oral health behavior, socio-economic, and medical variables $(n=106)$ were identified. These variables were then entered into final PCA/PLS models for caries and enamel defects.

Analyses were performed using SPSS version 23 (IBM Corporation, Armonk, NY, USA). SIMCA P+ version 12.0 (Umetrics $\mathrm{AB}$, Umeå, Sweden) was used for PCA and PLS modeling.

\section{Power calculation}

Dental caries was the primary outcome measure, and secondary outcomes were enamel defects and LL37 levels in saliva. G*Power (http://www.gpower.hhu.de/) was used to calculate the power to find a statistically significant difference in mean vitamin $\mathrm{D}$ levels between children with or without caries given the number and distribution of participants. With 85 participants, $\alpha=$ 0.05 , an effect size of 0.6 (difference in group means $=12$ and $\mathrm{SD}=18$ based on the distribution of all serum values), and two-tailed testing, we have $77 \%$ power to detect a statistically significant difference.

\section{Results}

Vitamin D status and other participants' characteristics

Vitamin D status before and after the intervention in the basic DViSUM cohort $(n=206)$ and the children in the dental subgroup $(n=85)$ are presented in Table 1 together with information on dietary intake. Additional information for the DViSUM basic study is found in Karlsland Åkeson et al. and Öhlund et al. [21, 22]. The overall $(\mathrm{n}=206)$ mean vitamin $\mathrm{D}$ level was $55.4 \mathrm{nmol} / \mathrm{L}$ (95\% CI: $52.8,58.0)$ at baseline with a mean increase of $30 \%$ in the high and $19 \%$ in the low intervention groups and no change in the placebo group (23). This result were in accordance with the levels found in the subgroup employed in the present study, i.e., $60.4 \mathrm{nmol} / \mathrm{L}$ (95\% CI: $56.4,64.3)$ and $76.3 \mathrm{nmol} / \mathrm{L}$ (95\% CI: 72.2, 80.3) at baseline and follow-up, respectively (Table 1). However, children who participated in the dental follow-up study had $8 \mathrm{nmol} / \mathrm{L}$ higher vitamin D levels at baseline and 3-month follow-up than those who did not (both $p=0.002$ ). Skin complexion and vitamin $\mathrm{D}$ intake from fortified milk and spreads were identified as the major determinants for vitamin D status in the DViSUM cohort [21]. A larger proportion of children who participated in the dental follow-up study had fair skin compared to those who did not (68 and $41 \%$, respectively; $p=0.001$ ), but their reported milk and fish intakes were similar (Table 1). Intake of sweet products was not monitored at 6 years of age, but at 8 years of age, intake of several sweet products was common. Mean intake of products with added sucrose was 1.7 times per day (Table 1).

Similar to in the basic DViSUM cohort [21, 22], serum $25(\mathrm{OH}) \mathrm{D}$ levels varied by skin type and region of residence in the dental subgroup. Thus, children with darker skin $(n=27)$ had significantly lower $25(\mathrm{OH}) \mathrm{D}$ levels than children with fair skin $(n=58)$ (mean (95\% CI): $49.4(42.0$, $56.8)$ and $65.4(61.3,69.6) \mathrm{nmol} / \mathrm{L}$, respectively, $p<0.001)$. In the former group, $59.3 \%$ had insufficient levels compared with $13.8 \%$ in the latter group $(\mathrm{p}<0.001)$. Further, children in southern Sweden had significantly lower S-25 
Table 1 Vitamin D status and diet intake in 6 year olds in the DViSUM study group $(n=206)$ and in the nested dental study subgroup $(n=85)$. Data are presented as mean with $95 \% \mathrm{Cl}$. ND = not determined

\begin{tabular}{|c|c|c|c|}
\hline & \multirow{2}{*}{$\begin{array}{l}\text { DViSUM } \\
\begin{array}{l}6 \text { years of age } \\
n=206\end{array}\end{array}$} & \multicolumn{2}{|c|}{ Dental study sub-group } \\
\hline & & $\begin{array}{l}6 \text { years of age } \\
n=85\end{array}$ & $\begin{array}{l}8 \text { years of age } \\
n=85\end{array}$ \\
\hline \multicolumn{4}{|l|}{ Vitamin D status, nmol/L } \\
\hline at baseline & $55.4(52.8,58.0)$ & $60.4(56.4,64.3)$ & ND \\
\hline after intervention & $71.5(68.6,74.3)$ & $76.3(72.2,80.3)$ & ND \\
\hline \multicolumn{4}{|l|}{ Intake of vitamin D foods } \\
\hline Milk $^{a}, \mathrm{~mL} /$ day & $535(484,587)$ & $562(478,646)$ & $574(521,629)$ \\
\hline Cheese $^{b}, g /$ day & $20.0(13.5,26.5)$ & $14.7(9.9,19.2)$ & $17(12,22)$ \\
\hline Eggs, g/day & $13.4(8.2,18.5)$ & $14.4(12.5,17.6)$ & ND \\
\hline Fatty fish, g/day & $14(11.7,17.5)$ & $14.2(12.6,17.2)$ & $13(9,16)$ \\
\hline Table spreads, g/day & $19.7(17.9,21.5)$ & $20.9(17.9,23.9)$ & ND \\
\hline Vitamin D supplement, $\%$ with reported intake & 14 & 10 & 34 \\
\hline \multicolumn{4}{|l|}{ Intake of sweet products } \\
\hline Sum of sucrose product, frequency/day & ND & ND & $1.7(1.1,2.3)$ \\
\hline Sodas with sucrose, frequency/day & ND & ND & $0.4(0.3,0.5)$ \\
\hline Cookies and sweet buns, frequency/day & ND & ND & $0.53(0.28,0.79)$ \\
\hline Non-sweet snacks, frequency/day ${ }^{c}$ & ND & ND & $0.15(0.12,0.18)$ \\
\hline Fruits, frequency/day & ND & ND & $1.5(1.3,1.7)$ \\
\hline
\end{tabular}

including non-fermented milk, sour milk, and yoghurt (natural and sweetened)

$\mathrm{b}_{\text {including cheese, and cottage cheese }}$

cincluding crisps, cheese doodles, popcorn

$(\mathrm{OH}) \mathrm{D}$ levels than children in northern Sweden (mean $(95 \% \mathrm{CI}): 54.7(48.9,60.4)$ and $64.9(59.7,70.1)$, respectively; $p=0.009)$. Insufficient S-25 (OH)D levels were seen in $42.1 \%$ in the former compared to $17.0 \%$ in the latter group $(p=0.011)$.

\section{Vitamin D and caries status}

Caries-affected children had a mean of 4.5 decayed or filled tooth surfaces (dfs/DFS) (95\% CI: $3.3,5.8)$ at 8 years of age (Table 2). In univariate analyses, vitamin D levels did not differ between children with or without caries, although the proportion with $<50 \mathrm{nmol} / \mathrm{L}$ of $\mathrm{S}-25[\mathrm{OH}] \mathrm{D}$ tended to be higher among children with caries (Table 2). dfs/DFS scores did not differ significantly between the three vitamin D intervention groups $[2.5(0,6.3), 2.1$ $(1.0,3.1)$ and $1.7(0.7,2.7)$ for 2,10 and $25 \mu \mathrm{g}$, respectively; $p=0.758$ ]. Children with $<50 \mathrm{nmol} / \mathrm{l}$ of $\mathrm{S}$ $25[\mathrm{OH}] \mathrm{D}$ after the intervention had a mean $\mathrm{dfs} / \mathrm{DFS}$ of 5.8 compared to 1.4 for those with $>50 \mathrm{nmol} / \mathrm{L}$ ( $p=$ 0.001). The trend was similar for the baseline $S$ 25[OH]D strata (2.9 versus 1.6: $p=0.086)$. A darker skin complexion was significantly more common among those with caries than without ( $p=0.014$, Table 2). No association was seen between caries status and reported intake frequency of any sweet or other food item assessed in the questionnaire (data not shown). The proportions reporting vitamin D supplement intake did not differ between caries groups (Table 2) or vitamin D intervention groups (data not shown), but it was more common among children who had an insufficient vitamin D status or not at baseline (58\% and 25\%, $p=0.004)$ and after the intervention ( $78 \%$ and $30 \%, p=0.005)$. Notably, after the second blood analyses, parents were informed about the child's vitamin D status and supplements were recommended for those with low levels. This recommendation was reflected in that at 8 years of age, 34\% reported intake of a vitamin D supplement compared to $14 \%$ before the intervention started (Table 1).

As a next step, we evaluated the risk of developing caries according to vitamin $\mathrm{D}$ levels (continuous measure) at baseline and after the 3-month intervention using a logistic regression model that included potential confounders. In the basic model (model 1), higher baseline vitamin $\mathrm{D}$ levels were significantly associated with less caries [OR (95\% CI) $0.961(0.929,0.995 ; p=0.024)$ ] which remained after Firth's correction (Table 3). Additional adjustments for BMI and reported intake of vitamin D supplement at caries examination attenuated the results slightly $(0.967(0.931,1.005 ; p=0.085)$; Table 3$)$ and they were no longer statistically significant after Firth's correction. The results were similar when vitamin $D$ levels at follow-up were used as the independent variable (Table 3). Backward elimination indicated that S- 
Table 2 Characteristics of dental study group participants by caries status. Data are presented as mean with $95 \% \mathrm{Cl}$ for continuous measures and proportion (\%) for categorical measures. Differences between groups were tested with Students t-test and Chi-square test, respectively

\begin{tabular}{|c|c|c|c|}
\hline & $\begin{array}{l}\text { Caries-free } \\
n=48\end{array}$ & $\begin{array}{l}\text { Caries } \\
n=37\end{array}$ & p-value \\
\hline \multicolumn{4}{|l|}{ Baseline } \\
\hline Age years, mean (95\% Cl) & $6.4(6.2,6.6)$ & $6.3(6.0,6.5)$ & 0.259 \\
\hline Boys, \% & 52.1 & 32.4 & 0.070 \\
\hline Region, south; north, \% & $52.1 ; 47.9$ & $35.1 ; 64.9$ & 0.119 \\
\hline Fair; darker skin, \% & $79.2 ; 20.8$ & $54.1 ; 45.9$ & 0.014 \\
\hline Mother education, $\% \geq 12$ years & 56.3 & 51.4 & 0.653 \\
\hline Father education, $\% \geq 12$ years & 68.1 & 51.4 & 0.126 \\
\hline BMI, z-score & $0.23(-0.06,0.52)$ & $0.29(-0.03,0.62)$ & 0.764 \\
\hline Vitamin D supplement, \% with reported intake & 31.3 & 38.9 & 0.466 \\
\hline Insufficient vitamin D status, \% & 20.8 & 37.8 & 0.084 \\
\hline $\mathrm{S}-25(\mathrm{OH}) \mathrm{D}, \mathrm{nmol} / \mathrm{L}$ & $62.6(57.3,67.8)$ & $57.4(51.3,63.5)$ & 0.195 \\
\hline S-Calcium, mmol/L & $2.43(2.41,2.45)$ & $2.45(2.43,2.47)$ & 0.339 \\
\hline S-Phosphate, mmol/L & $1.57(1.53,1.61)$ & $1.51(1.46,1.55)$ & 0.033 \\
\hline S-Magnesium, mmol/L & $0.88(0.86,0.89)$ & $0.85(0.84,0.87)$ & 0.015 \\
\hline Parathyroid hormone (PTH), pmol/L & $3.86(3.47,4.30)$ & $3.68(3.32,4.04)$ & 0.512 \\
\hline Osteocalcin, $\mu \mathrm{g} / \mathrm{L}$ & $86.2(79.1,93.4)$ & $81.3(73.1,89.6)$ & 0.364 \\
\hline Alkaline phosphatase, $\mu$ kat/L & $3.94(3.71,4.16)$ & $3.99(3.62,4.35)$ & 0.812 \\
\hline \multicolumn{4}{|l|}{ Dental examinations } \\
\hline Age, years & $8.3(8.1,8.5)$ & $8.1(7.8,8.3)$ & 0.258 \\
\hline \multicolumn{4}{|l|}{ Number of teeth } \\
\hline total number & $23.5(23.2,23.7)$ & $22.9(22.4,23.5)$ & 0.059 \\
\hline deciduous teeth & $11.5(10.7,12.3)$ & $11.5(10.6,12.5)$ & 0.968 \\
\hline permanent teeth & $12.0(11.2,12.7)$ & $11.4(10.5,12.4)$ & 0.368 \\
\hline Caries status score (dfs/DFS) & 0 & $4.5(3.3,5.8)$ & $<0.001$ \\
\hline \multicolumn{4}{|l|}{ Enamel defects } \\
\hline single tooth, $\%$ & 62.5 & 63.9 & 0.896 \\
\hline multiple teeth, \% & 45.8 & 44.4 & 0.899 \\
\hline Tooth brushing twice a day, \% & 88.9 & 94.3 & 0.397 \\
\hline \multicolumn{4}{|l|}{ Saliva analyses } \\
\hline $\mathrm{LL} 37, \mathrm{ng} / \mathrm{mL}$ & $1.01(0.74,1.29)$ & $1.56(1.24,1.88)$ & 0.012 \\
\hline S. mutans, $\%$ positive by PCR & 27.1 & 33.3 & 0.535 \\
\hline S. sobrinus $\%$ positive by PCR & 0 & 0 & - \\
\hline
\end{tabular}

$25[\mathrm{OH}] \mathrm{D}$ levels at baseline, tooth brushing, number of teeth, and living region were independently associated with having caries $(p=0.01$, Table 3$)$.

Finally, PLS modeling was applied with caries status (yes/no) as dependent variables and variables with a screening VIP value $>1$ in the independent block. PLS identified one significant component with an explanatory $\left(\mathrm{R}^{2}\right)$ and predictive $\left(\mathrm{Q}^{2}\right)$ capacity of $29.8 \%$ and $12.1 \%$, respectively. Having caries was significantly associated with number of siblings, skin color and type, and having less than $50 \mathrm{nmol} / \mathrm{l}$ of 25(OH)D levels in serum (Fig. 2).
Being caries-free was significantly associated with higher levels of magnesium, phosphate and $25(\mathrm{OH}) \mathrm{D}$ in serum (Fig. 2).

\section{Vitamin D status and enamel defects}

The prevalence of enamel defects on the permanent first molars and central upper and lower incisors did not differ between children with insufficient and sufficient vitamin D levels at 6 years of age. Six children had serum vitamin $\mathrm{D}$ levels corresponding to a vitamin $\mathrm{D}$ deficiency, i.e., $<30 \mathrm{nmol} / \mathrm{L}$, and 4 of 
Table 3 Odds ratios to have dental caries or not by increasing vitamin D status. Serum vitamin D levels are at 6 years of age and caries status at 8 years of age

\begin{tabular}{|c|c|c|c|c|c|c|}
\hline & \multicolumn{6}{|c|}{ Logistic regression } \\
\hline & \multicolumn{3}{|l|}{ Baseline } & \multicolumn{3}{|c|}{3 months after intervention } \\
\hline & Odds ratio & $95 \% \mathrm{Cl}$ & $p$-value & Odds ratio & $95 \% \mathrm{Cl}$ & $p$-value \\
\hline \multicolumn{7}{|c|}{ Method: Variables entered } \\
\hline Model $1^{\mathrm{a}}$ & 0.961 & $0.929,0.995$ & 0.024 & 0.966 & $0.936,0.997$ & 0.030 \\
\hline Model $2^{b}$ & 0.962 & $0.928,0.998$ & 0.037 & 0.971 & $0.939,1.003$ & 0.075 \\
\hline Model $3^{c}$ & 0.967 & $0.931,1.005$ & 0.085 & 0.975 & $0.943,1.009$ & 0.148 \\
\hline \multicolumn{7}{|l|}{ With Firth's correction } \\
\hline Model $1^{\mathrm{a}}$ & 0.966 & $0.935,0.998$ & 0.040 & 0.969 & $0.940,0.999$ & 0.044 \\
\hline Model $2^{b}$ & 0.970 & $0.935,1.008$ & 0.117 & 0.975 & $0.943,1.008$ & 0.134 \\
\hline Model $3^{c}$ & 0.973 & $0.936,1.010$ & 0.153 & 0.979 & $0.947,1.013$ & 0.232 \\
\hline \multicolumn{7}{|c|}{ Method: Backward elimination (variables retained in final model) } \\
\hline D vitamin status & 0.958 & $0.926,0.990$ & 0.01 & 0.971 & $0.940,1.003$ & 0.08 \\
\hline Number of teeth & 0.666 & $0.412,1.061$ & 0.087 & 0.598 & $0.366,0.975$ & 0.039 \\
\hline Living region $^{d}$ & 3.13 & $1.05,9.33$ & 0.040 & 2.62 & $0.842,8.16$ & 0.096 \\
\hline Tooth brushing $^{d}$ & 0.099 & $0.008,1.16$ & 0.065 & \multicolumn{3}{|l|}{ Not retained } \\
\hline Skin type ${ }^{d}$ & Not retained & & & 3.08 & $1.02,9.35$ & 0.047 \\
\hline
\end{tabular}

${ }^{a}$ Model 1 with caries (yes/no) as dependent variables and serum levels of vitamin D, number of teeth, tooth brushing, S. mutans, parental education, and living region as covariates

${ }^{\mathrm{b}}$ model $1+\mathrm{BMI}$, and reported intake of vitamin $\mathrm{D}$ supplement at the caries examination

cmodel $2+$ skin type

${ }^{\mathrm{d}}$ The reference categories were southern Sweden (living region), brushing <twice a day (tooth brushing), and fair skin (skin type)

these children had multiple enamel defects on the assessed teeth, but 2 did not. Thus, in this population, baseline levels of S-25 $(\mathrm{OH}) \mathrm{D}$ or any of the other serum components did not differ between the children with or without enamel defects on the permanent first molars and central upper and lower incisors (data not shown).

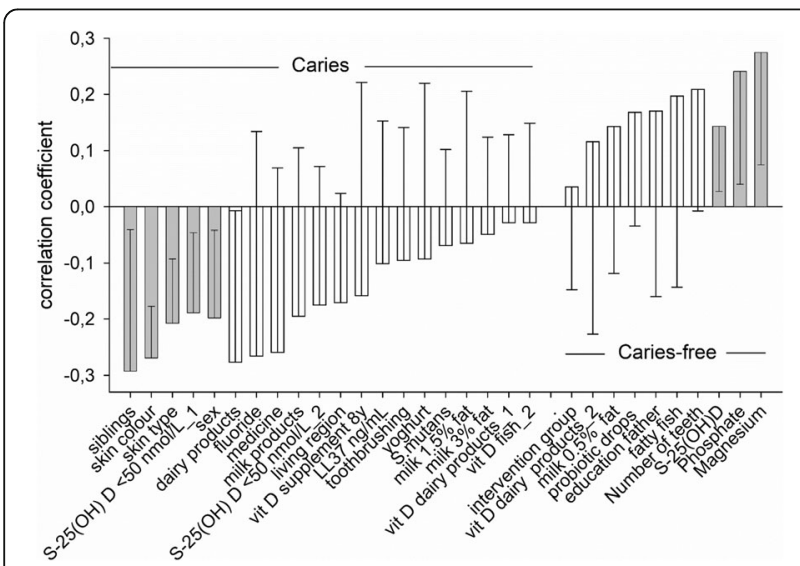

Fig. 2 PLS correlation coefficients from multivariate modelling with caries status (yes/no) as dependent variables. Correlation coefficients with $95 \% \mathrm{Cl}$ for the variables in the final mode are presented. Bars for which the $95 \%$ whisker do not pass zero are statistically significant
PLS modeling only identified intake of a vitamin D supplement at 8 years of age as associated with having defects, which likely reflects reversed causality.

\section{Vitamin D status and LL37 levels in saliva}

LL37 is an innate immunity peptide for which expression has been linked to vitamin D status [4]. In the dental study group, region-adjusted mean LL37 levels were lower in children with insufficient serum vitamin $\mathrm{D}$ status than in children with serum $25(\mathrm{OH}) \mathrm{D}$ levels $\geq 50 \mathrm{nmol} / \mathrm{L}$ after the 3-month intervention [1.09 (0.87, $1.30)]$ and $[2.38(1.77,2.99)$, respectively; $p<0.001]$. No difference was observed in LL37 levels between children who reported vitamin D supplement intake at 8 years of age or not. The mean LL37 levels in saliva (adjusted for region of residence) were higher among children who had caries at 8 years of age.

\section{Discussion}

The primary goal of the present study was to evaluate the association between vitamin $\mathrm{D}$ status and prospective caries status in children selected from a population with overall low caries prevalence, high milk consumption and vitamin D supplementation in infancy [21,30]. The results support an inverse association between vitamin D status and caries, i.e., higher vitamin D and less 
caries, although the results were not fully consistent. No association was found with enamel defects.

Most studies evaluating the association between vitamin D status and dental caries use a cross-sectional design [14, 31]. Caries development is normally a slow process with several years of delay before a cavity is observed. Therefore, the serum $25(\mathrm{OH}) \mathrm{D}$ level at the time of caries scoring may or may not be representative of the period when caries symptoms developed [14]. Therefore, we examined the participants' caries status 2 years after vitamin D levels were assessed. Although the participants' vitamin D status was not followed during the two years between the initial vitamin $\mathrm{D}$ measurement and dental examination, information on vitamin D supplement intake at the time of the dental examination was available. The children in the present study were nested in a study in which vitamin D status was analyzed before and after a 3-month treatment with milk-based supplements with different vitamin D concentrations at 6 years of age. When the follow-up blood samples were analyzed, parents of children with serum levels $<50 \mathrm{nmol} / \mathrm{L}$ were advised to administer a vitamin D supplement to their children. We have no information on individual compliance with this advice, but at the time of dental examination, $78 \%$ of children with $<50 \mathrm{nmol} / \mathrm{L}$ (insufficient vitamin D status) in their second blood sample reported that the child was given a vitamin D supplement. Therefore, one might hypothesize that the serum $25(\mathrm{OH}) \mathrm{D}$ levels measured after the intervention would better reflect the levels over the 2-year interval for most study subjects. On the other hand, the results from the models employing the baseline values may better reflect habitual levels and the situation during the period between 2 and 6 years of age when teeth mineralized and caries development likely began. However, to be able to assess the associations properly, the question should be addressed in a longitudinal study with repeated measures of both serum 25(OH)D levels and caries status from early childhood to the age of caries scoring and should include children with more selective diets. In the present study, consuming milk was an inclusion criterion.

The saliva LL37 concentration was lower in children who had an insufficient D vitamin levels than in children who had sufficient serum levels at follow-up. This result was stable in sensitivity analyses stratified by supplement intake at 8 years of age. LL37, a 37-amino acid peptide generated from proteolytic cleavage of the extracellular domain of the $18-\mathrm{kDa}$ hCAP18 protein from epithelial cells and neutrophils [32, 33], is the only cathelicidinderived antibacterial peptide in humans. Vitamin D has been shown to have a specific role in the expression of the cathelicidins, and several studies have confirmed the association between vitamin D and LL37 levels [4]. LL37 has been linked to several biological innate immune functions, including those in periodontal disease and psoriasis [34, 35]. LL37 has also been implicated in the oral microbiota, but the results from studies on its association with dental caries are inconsistent [36, 37]. In the present study, children with caries had higher LL37 levels, which may indicate oral microbiota-induced expression. Although these findings are consistent with some previous publications $[38,39]$, the results should be interpreted with caution and evaluated in a larger study in which vitamin D status is measured closer to the time of LL37 analysis.

According to previous studies, enamel defects in the form of opacities and hypomineralization are more prevalent in patients with vitamin D deficiency [40]. In the present population, the prevalence of enamel defects on permanent first molars or central incisors did not differ between children with serum levels $<50 \mathrm{nmol} / \mathrm{L}$ at 6 years of age and children with sufficient vitamin $\mathrm{D}$ at this age. This finding was expected since the evaluated teeth were mineralized during the first years of life, and all parents in Sweden are encouraged to provide vitamin $D_{3}$ supplements of $10 \mu \mathrm{g} /$ day in drop form to their children from birth to 2 years of age. The drops are available free of charge. Children with dark skin, or those with little outdoor activity, and children who do not receive fortified products or eat fish are advised to continue taking the vitamin D drops up to 5 years of age $[29,41]$. Therefore, during these early years, intake from supplements rather than UV light exposure is likely to be the major determinant of vitamin D status. This hypothesis was also supported by the finding that the prevalence of enamel defects on the specified teeth did not differ between children with fair or dark skin in the present study, even though their vitamin D status differed at 6 years of age.

The strengths of the present study include that vitamin D status was measured and not based on selfreported intake only, that caries were evaluated prospectively and were scored by experienced pediatric dentists who took X-rays when approximal surfaces were not accessible and that the study group was very well characterized. However, there are limitations that should be acknowledged when the results are interpreted. The study group is small with limitations in stratification, vitamin D status was not reanalyzed later than the intervention follow-up, and there is a potential risk of response bias in the questionnaire replies. It should also be acknowledged that the study group represents populations characterized by vitamin D supplementation in the first living years and regular dental care.

\section{Conclusions}

Based on the present results, we conclude that the results from Schroth et al. [14] of an inverse association between 
vitamin D status and caries were supported. However, the comparably small study group and weak association with attenuation from confounder adjustment suggest the need for replication. Vitamin D status was unrelated to enamel defects on permanent incisors and molars in the present circumstances, whereas an association between vitamin D status and LL37 levels was supported.

\section{Abbreviations}

ALP: Alkaline Phosphatase; BMI: Body Mass Index; Cl: Confidence Interval limit; DFS: Decayed Filled Surface; GLM: General Linear Modelling; OR: Odds ratio; PCA: Principal Component Analysis; PCR: Polymerase Chain Reaction; PLS: Partial Least Square Regression analysis; PTH: ParaThyroid Hormone; PuL: Swedish law on personal data act

\section{Acknowledgements}

The basic DViSUM study was funded by grants from Dr. Per Håkansson Foundation, the Fanny Ekdahl foundation, the Samariten Foundation, the Oskar Foundation, the Jerring Foundation, and through Västerbotten County Council in the field of Medicine, Odontology, and Health (ALF) and the present dental follow-up study by Umeå University and TUA, the Västerbotten County Council, Sweden. Funders had no role in study design, data collection and analysis, decision to publish, or preparation of the manuscript. Carina Öhman and Agneta Rönnlund are acknowledged for skilful laboratory work.

\section{Funding}

The present study was funded by Umeå University, and TUA, the County Council of Västerbotten, Sweden.

\section{Availability of data and materials}

The datasets generated during the current study are not publicly available due ethical restrictions but are available from the corresponding author on reasonable request.

\section{Authors' contributions}

PLH designed the study, JG and KR performed the clinical examination and $J G, K R$ and PLH analysed the photos, IÖ and PKÅ were responsible for the basic study from which participants were recruited and serum and some questionnaire data were obtained, IJ performed the data analyses and wrote the manuscript, and all authors read and approved of the final article.

\section{Competing interest}

The authors declare that they have no competing interests.

\section{Ethics approval and consent to participate}

Approval of the study was given by the Regional Ethical Review Board in Umeå, Sweden (References 2012-158-31 M and 2014-103-32 M). Prior to inclusion, each subject got a full written and oral explanation of the purpose and procedure of the study and written informed consent was obtained from the caregivers of the children.

\section{Consent for publication}

Not applicable.

\section{Publisher's Note}

Springer Nature remains neutral with regard to jurisdictional claims in published maps and institutional affiliations.

\section{Author details}

'Department of Odontology, Section of Paediatric Dentistry, Faculty of Medicine, Umeå University, 90185 Umeå, Sweden. ${ }^{2}$ Department of Paediatric Dentistry, Faculty of Odontology, Malmö University, Malmö, Sweden. ${ }^{3}$ Department of Clinical Sciences/Section of Paediatric Medicine, Faculty of Medicine, Umeå University, Umeå, Sweden. ${ }^{4}$ Department of Clinical Sciences, Pediatrics, Lund University, Lund, Malmö, Sweden. ${ }^{5}$ Department of Odontology/Section of Cariology, Faculty of Medicine, Umeå University, Umeå, Sweden.
Received: 26 June 2017 Accepted: 4 January 2018

Published online: 16 January 2018

\section{References}

1. Reichrath J, Saternus R, Vogt T. Challenge and perspective: the relevance of ultraviolet (UV) radiation and the vitamin D endocrine system (VDES) for psoriasis and other inflammatory skin diseases. Photochem Photobiol Sci. 2017;16:433-44.

2. Svensson D, Nebel D, Nilsson B-O. Vitamin D3 modulates the innate immune response through regulation of the hCAP-18/LL-37 gene expression and cytokine production. Inflamm Res. 2016;65:25-32.

3. Davideau JL, Lezot F, Kato S, Bailleul-Forestier I, Berdal A. Dental alveolar bone defects related to vitamin D and calcium status. J Steroid Biochem Mol Biol. 2004;89:615-8.

4. Raftery T, Martineau AR, Greiller $C L$, et al. Effects of vitamin D supplementation on intestinal permeability, cathelicidin and disease markers in Crohn's disease: results from a randomised double-blind placebocontrolled study. United European Gastroenterol J. 2015;3:294-302.

5. Abhimanyu, Coussens A. The role of UV radiation and vitamin D in the seasonality and outcomes of infectious disease. Photochem Photobiol Sci. 2017;16:314-38.

6. Skaaby T, Nystrup Husemoen LL, Pisinger C, et al. Vitamin D status and incident cardiovascular disease and all-mortality: a general population study. Endocrine. 2013:43:618-25.

7. Institute of Medicine. Dietary reference intakes for calcium and vitamin D. Washington (DC): The National Academic Press. 2011.

8. Greer FR. 25-Hydroxyvitamin D: functional outcomes in infants and young children. Am J Clin Nutr. 2008;88:529S-33S.

9. Vieth R. Why the minimum desirable serum 25-hydroxyvitamin D level should be $75 \mathrm{nmol} / \mathrm{L}(30 \mathrm{ng} / \mathrm{ml})$. Best Pract Res Clin Endocrinol Metab. 2011; 25:681-91.

10. Prentice A, Goldberg GR, Schoenmakers I. Vitamin D across the lifecycle: physiology and biomarkers. Am J Clin Nutr. 2008:88:500S-6S.

11. Clemens TL, Adams JS, Henderson SL, Holick MF. Increased skin pigment reduces the capacity of skin to synthesise vitamin D3. Lancet. 1982;1:74-6.

12. Öhlund I, Silfverdal SA, Hernell O, Lind T. Serum 25-hydroxyvitamin D levels in preschool children in northern Sweden are inadequate after summer and diminish further during winter. J Pediatr Gastroenterol Nutr. 2013;56:551-5.

13. Schroth RJ, Lavelle C, Tate R, Bruce S, Billings RJ, Moffatt MEK, Prenatal Vitamin D. Dental caries in infants. Pediatrics. 2014;133:277.

14. Schroth RJ, Rabbani R, Loewen G, Moffatt ME. Vitamin D and Dental caries in children. J Dent Res. 2016;95:173-9.

15. Dudding T, Thomas SJ, Duncan K, Lawlor DA, Timpson NJ. Re-examining the association between vitamin D and childhood caries. PLoS One 2015;21: 10:e0143769.

16. Herzog K, Scott JM, Hujoel P, Seminario AL. Association of vitamin D and dental caries in children: findings from the National Health and nutrition examination survey, 2005-2006. J Am Dent Assoc. 2016;147: $413-20$.

17. Theodoratou E, Tzoulaki I, Zgaga L, loannidis JP, Vitamin D. Multiple health outcomes: umbrella review of systematic reviews and meta-analyses of observational studies and randomised trials. BMJ. 2014;348:2035.

18. Hujoel PP, Vitamin D. Dental caries in controlled clinical trials: systematic review and meta-analysis. Nutr Rev. 2013;71:88-97.

19. Karpiński M, Galicka A, Milewski R, Popko J, Badmaev V, Stohs SJ. Association between vitamin $D$ receptor polymorphism and serum vitamin $D$ levels in children with low-energy fractures. J Am Coll Nutr. 2017;9:1-8.

20. Mäkinen M, Mykkänen J. Koskinen et al. serum 25-hydroxyvitamin D concentration in children progressing to autoimmunity and clinical type 1 diabetes. J Clin Endocrinol Metab. 2016;101:723-9.

21. Åkeson PK, Lind T, Hernell O, Silfverdal SA, Öhlund I, Serum Vitamin D. Depends less on latitude than on skin color and dietary intake during early winter in northern Europe. J Pediatr Gastroenterol Nutr. 2016;62:643-9.

22. Öhlund I, Lind T, Hernell O, Silfverdal SA, Karlsland Åkeson P. Increased vitamin $D$ intake differentiated according to skin color is needed to meet requirements in young Swedish children during winter: a double-blinded randomized clinical trial. Am J Clin Nutr. 2017:jun 14. ajcn147108.

23. www.livsmedelsverket.se/globalassets/english/food-habits-health-environment/ dietary-guidelines/good-food-for-children-1-2-years (2017-06-09).

24. World Health Organization. Oral health surveys: basic methods 4th edition 1997. World Health Organization, Geneva. 
25. A review of the developmental defects of enamel index (DDE-Index). Commission on Oral Health, Research \& Epidemiology. Report of an FDI Working Group. Int Dent J. 1992; 42:411-26.

26. Lif Holgerson P, Harnevik L, Hernell O, Tanner AC, Johansson I. Mode of birth delivery affects oral microbiota in infants. J Dent Res. 2011;90:1183-8.

27. Yano A, Kaneko N, Ida H, Yamaguchi T, Hanada N, Real-time PCR. For quantification of Streptococcus Mutans. FEMS Microbiol Lett. 2002;19: 23-30.

28. de Onis M, Onyango AW, Borghi E, Siyam A, Nishida C, Siekmann J. Development of a WHO growth reference for school-aged children and adolescents. Bull World Health Organ. 2007:85:660-7.

29. Ross AC, Manson JE, Abrams SA, et al. The 2011 report on dietary reference intakes for calcium and vitamin D from the Institute of Medicine: what clinicians need to know. J Clin Endocrinol Metab. 2011;96:53-8.

30. Nordic Council of Ministers. Nordic Nutrition Recommendations 2012 Nordic Nutrition Recommendations 2012 2012;5(11):1.

31. Guizar JM, Muñoz N, Amador N, Garcia G. Association of Alimentary Factors and Nutritional Status with caries in children of Leon, Mexico. Oral Health Prev Dent. 2016;14:563-9.

32. Larrick JW, Hirata M, Balint RF, Lee J, Zhong J, Wright SC. Human CAP18: a novel antimicrobial lipopolysaccharide-binding protein. Infect Immun. 1995; 63:1291-7.

33. Yamasaki K, Schauber J, Coda A, et al. Kallikrein-mediated proteolysis regulates the antimicrobial effects of cathelicidins in skin. FASEB J. 2006;20: 2068-80.

34. Gomes Pde S, Fernandes MH. Defensins in the oral cavity: distribution and biological role. J Oral Pathol Med. 2010;39:1-9.

35. Lande R, Botti E, Jandus C, et al. The antimicrobial peptide LL37 is a T-cell autoantigen in psoriasis. Nat Commun. 2014;5:5621.

36. Tao R, Jurevic RJ, Coulton KK. Salivary antimicrobial peptide expression and dental caries experience in children. Antimicrob Agents Chemother. 2005; 49:3883-8.

37. Phattarataratip E, Olson B, Brofitt B, et al. Streptococcus Mutans strains recovered from caries-active or caries-free individuals differ in sensitivity to host antimicrobial peptides. Mol Oral Microbiol. 2011;26:187-99.

38. Colombo NH, Ribas LF, Pereira JA, et al. Antimicrobial peptides in saliva of children with severe early childhood caries. Arch Oral Biol. 2016:69:40-6.

39. Malcolm J, Sherriff A, Lappin DF, et al. Salivary antimicrobial proteins associate with age-related changes in streptococcal composition in dental plaque. Mol Oral Microbiol. 2014;29:284-93.

40. Künisch J, Thiering E, Kratzsch J, Heinrich- Weltzien R, Hickel R, Heinrich J. Elevated serum $25(\mathrm{OH})$-vitamin $\mathrm{D}$ levels are negatively correlated with molar-incisor hypomineralisation. J Dent Res. 2015;94:381-7.

41. https://www.livsmedelsverket.se/livsmedel-och innehall/naringsamne/ vitaminer-och-antioxidanter/vitamin-d/ (2017-01-27).

\section{Submit your next manuscript to BioMed Central and we will help you at every step:}

- We accept pre-submission inquiries

- Our selector tool helps you to find the most relevant journal

- We provide round the clock customer support

- Convenient online submission

- Thorough peer review

- Inclusion in PubMed and all major indexing services

- Maximum visibility for your research

Submit your manuscript at www.biomedcentral.com/submit

) Biomed Central 